\title{
Las pullas de Isabel(a) entre Lope y Góngora: modelos, versos y paratextos de Virtud, pobreza y mujer
}

\author{
Daniel Fernández Rodríguez* \\ Universitat de València \\ daniel.fernandez-rodriguez@uv.es
}

Recepción: 19/04/2021, Aceptación: 07/07/2021, Publicación: 22/12/2021

\begin{abstract}
Resumen
El presente artículo aborda la relación entre dos comedias: Las firmezas de Isabela, de Luis de Góngora, y Virtud, pobreza y mujer, de Lope de Vega. Tras fijar la fecha de escritura de la segunda, se estipula que fue Lope quien pudo inspirarse en Góngora y no al revés (cuestión discutida), y se aclaran, amplían, matizan o desmienten las huellas de la comedia gongorina atisbadas hasta ahora por la crítica. Además, se explica cómo el rastro de Las firmezas de Isabela se deja sentir fundamentalmente en el primer acto de Virtud, pobreza y mujer, mientras que en el resto de su comedia Lope se cińe a otros modelos (el género bizantino y una novella de Masuccio); del mismo modo, se recalca que la asombrosa virtud de Isabel puede leerse a la luz de otros casos similares, muy ponderados en el Arte nuevo. Con todo, el carácter polémico y antigongorino de la dedicatoria que Lope antepuso a Virtud, pobreza y mujer al publicar la pieza en la Parte XX (1625), lo mismo que las reminiscencias biográficas con que el madrileño moldeó a su protagonista — sugeridas aquí por vez primera—, permiten concluir que, tanto a la hora de escribir Virtud, pobreza y mujer como de publicarla, Lope quiso lanzar una pulla contra la comedia de su eterno rival: punto de partida de la suya, sí, pero hija del cordobés al fin y al cabo, y fruto de una propuesta teatral que en buena medida suponía una reacción contra la del Fénix de los Ingenios.
\end{abstract}

\footnotetext{
* Este artículo se ha beneficiado de mi participación en los proyectos de investigación PGC2018-094395-BI00, financiado por el Ministerio de Ciencia, Innovación y Universidades, PID2019-104045GB-C54 y PID2019-104045GB-C51, financiados por el Ministerio de Ciencia e Innovación y por fondos FEDER.
} 


\title{
Palabras clave
}

Las firmezas de Isabela; Virtud, pobreza y mujer; Lope de Vega; Luis de Góngora; polémica; comedia bizantina; Masuccio Salernitano.

\begin{abstract}
English Title. "Las pullas de Isabel(a)" between Lope and Góngora: models, verses and paratexts of Virtud pobreza y mujer.

This article studies the relationship between two plays: Las firmezas de Isabela, by Luis de Góngora, and Virtud, pobreza y mujer, by Lope de Vega. After establishing the composition date of the latter, I will demonstrate that it was Lope who might have been inspired by Góngora, rather than the other way around (a debated issue). I will also consider the various different threads of Góngora's comedy pointed out by scholars. Furthermore, I will explore how traces of Las firmezas de Isabela can be seen in the first act of Virtud, pobreza y mujer, while in the rest of his play Lope follows other models (the Byzantine genre and a novella by Masuccio Salernitano). At the same time, it seems clear that Isabel's astonishing virtue is related to aspects of Lope's Arte nuevo. However, the controversial dedication that Lope wrote for his play when he published it in his Parte XX (1625), as well as the autobiographical echoes with which he dressed up his protagonist (which have hitherto remained hidden), suggest that Lope was determined -both by writing Virtud, pobreza y mujer and by publishing it - to defy Las firmezas de Isabela: a reference point for his own play, but one nevertheless written by his adversary, whose dramatic work was to a large extent a reaction against Lope's art.
\end{abstract}

\section{Keywords}

Las firmezas de Isabela; Virtud, pobreza y mujer; Lope de Vega; Luis de Góngora; controversy; Byzantine comedies; Masuccio Salernitano. 
Mucho debían de gustarle a Lope las novelle de los italianos, o sea, las de sus paisanos, que así se les puede considerar a efectos literarios cuando menos. Entre las razones que empujaron al Fénix a deleitarse con sus historias día sí y día también se contaría sin duda su natural solaz como lector, pero también, cómo no, y acaso en primera instancia, sus necesidades como escritor. Ávido a cada paso de inspiración para sus comedias, no le tembló el pulso a la hora de atropar cuantos materiales precisara para su confección, y no de otro modo procedieron sus cofrades en menesteres literarios y teatrales. Buen ejemplo de tal práctica es Virtud, pobreza y mujer, comedia bizantina cuyo semillero principal es una novela de Masuccio Salernitano, o acaso la versión —-más bien un plagio descarado, a qué engañarnos- que de ella publicase Niccolò Granucci. ${ }^{1}$ Pero resulta que, ya desde antiguo, la crítica ha resaltado también ciertas concomitancias entre la pieza de Lope y otra debida nada menos que a su archienemigo en lides poéticas: Las firmezas de Isabela, de Luis de Góngora. Estas páginas, que tanto deben a todos los estudiosos que se han ocupado del asunto, tratarán de poner orden y concierto en la agitada relación entre ambas obras para así aclarar, ampliar, matizar o desmentir las posibles huellas de Las firmezas de Isabela en Virtud, pobreza y mujer. ¿ $\mathrm{O}$ acaso fue al revés?

En efecto, si bien el grueso argumental de Virtud, pobreza y mujer es de ascendencia italiana, ciertos resortes dramáticos la emparentan con Las firmezas de Isabela. El primero en señalar la deuda de Lope con la pieza gongorina fue Robert Jammes (1967: 496-500). La posteridad se hizo poco eco de sus juicios. Así, durante los siguientes treinta años apenas topamos con una atenta revisión por parte de Laura Dolfi (1983: 279-282), quien en su imprescindible estudio sobre el teatro de Góngora constató que los paralelismos observados por el hoy llorado hispanista parecían "confermare la possibilità che Lope, al momento di scrivere la commedia, avesse ben presente la figura e l'opera del rivale cordovese», aun cuando se resistía a reconocer en ella una verdadera fuente y negaba, en la senda de algunos reparos y precisiones del propio Jammes - habrá tiempo de abordarlos-, «una cosciente imitazione» de Las firmezas de Isabela en Virtud, pobreza y mujer (Dolfi 1983: 281). Al año siguiente, en su edición de la comedia de Isabela, Jammes (1984: 24) volvió a insistir sucintamente en tal influjo, asunto al que Dolfi, en su posterior edición del teatro gongorino, publicada por vez primera en 1993 y actualizada y reeditada en fechas recientes (Dolfi 2016), no hizo ya mención alguna. En un artículo publicado en 2002, en cambio, Dolfi (2002: 50) citó brevemente la comedia de Lope, pero esta vez como fuente de Góngora y no a la inversa. Las indagaciones en la tesis de Jammes se deben sobre todo a Donald McGrady (2003), que dedicó un artículo exhaustivo a examinar el pa-

1. Fue Donald McGrady (2010: 7-11) quien descubrió el vínculo con la novela XXXIX de $I l$ Novellino de Masuccio, relación confirmada por Diana Berruezo (2015: 200-203); no obstante, la fuente de inspiración del Fénix pudo ser el plagio de Granucci (Fernández Rodríguez 2019a). 
rentesco entre ambas obras; el estudioso, sin embargo, sentenció que fue Góngora quien imitó a Lope, conclusión que él mismo corrigió luego en el prólogo a su edición de Virtud, pobreza y mujer (McGrady 2010), en el que pudo constatar que la comedia de Lope era posterior a Las firmezas de Isabela y, por consiguiente, dar la razón a Jammes, así como aportar nuevas semejanzas intertextuales. Quizá por no haber podido consultar la edición de McGrady, en un ensayo inmediatamente posterior Dolfi volvió a incluir Virtud, pobreza y mujer entre los hilos de los que se valió el cordobés para tejer Las firmezas de Isabela. ${ }^{2}$ Finalmente, Florence d'Artois (2014) ha renovado las tesis de Jammes, con indagaciones fundamentales acerca de la dedicatoria a Marino de Virtud, pobreza y mujer, ${ }^{3}$ aunque, al igual que Dolfi, tampoco cita la edición de McGrady, que por desgracia ha pasado algo desapercibida, a buen seguro por su escasa difusión en librerías y bibliotecas. En suma, la naturaleza de la relación entre ambas piezas ha topado con obstáculos importantes y está lejos de haber despertado el consenso oportuno entre la crítica, por lo que es urgente retomar su estudio con todos los datos sobre la mesa para, así, calibrar la posible repercusión de Las firmezas de Isabela en Virtud, pobreza y mujer.

Porque sí, digámoslo sin ambages: Lope podía conocer Las firmezas de Isabela cuando compuso Virtud, pobreza y mujer, pero Góngora, en cambio, no pudo contar con la pieza del Fénix para la comedia de Isabela, puesto que el cordobés la redactó en $1610,{ }^{4}$ mientras que el madrileño pergeñó la suya en 1616. Este último dato se desprende de varias referencias internas de Virtud, pobreza y mujer inadvertidas hasta ahora, ${ }^{5}$ que solventan por fin «le problème de la datation incertaine de la comedia" (d'Artois 2014: 102). ${ }^{6}$

Pero no solo es posible, sino más bien probable, que Lope hojease Las firmezas de Isabela. Durante los primeros meses de 1616, cuando hubo de preparar Virtud, pobreza y mujer, Isabela era una relativa novedad editorial, pues Antonio

2. «El recuerdo de la lopiana Virtud, pobreza y mujer se justifica fácilmente en Las firmezas de Isabela por la coincidente presencia de un protagonista mercader y desconfiado" (Dolfi 2011: 35). 3. Fausta Antonucci (2013) ha editado este jugoso paratexto; sus notas y comentarios son tan imprescindibles como las páginas que le dedica en otro trabajo (Antonucci 2014); ahora pueden verse también las notas a nuestra edición de la obra (Fernández Rodríguez 2021).

4. Es el año que aporta el manuscrito Chacón (Dolfi 2011: 14).

5. Se trata de una serie de acontecimientos ligados a personajes del momento, tales como el traslado del arzobispo Pedro González de Mendoza y Silva desde Granada a Zaragoza, que tuvo lugar el 8 de febrero de 1616 (Peinado Guzmán 2015), o la designación de Jorge de Cárdenas y Manrique, cuarto duque de Maqueda, como gobernador de Orán, oficializada a comienzos de 1616 (Alonso Acero 1997: 186 y 206). Desarrollo con detalle estos casos, y algún otro, en un trabajo reciente (Fernández Rodríguez en prensa).

6. Morley y Bruerton (1968: 269) le habían adjudicado el periodo comprendido entre 1612 y 1615, y se decantaron por 1615 como el año más probable; esta última fecha la refrendó McGrady (2010: 7 y 152), a raíz justamente del traslado de Pedro González de Mendoza y Silva, que situó erróneamente en 1615, cuando en verdad se produjo a principios de 1616 (véase la nota anterior). 
Sánchez la había publicado en 1613 como parte de las Cuatro comedias de diversos autores (Córdoba, Francisco de Cea). Por esas calendas, el teatro impreso no abundaba, y Lope ni siquiera se había hecho aún con las riendas del suyo, que circulaba sin su consentimiento, de suerte que una apuesta editorial como las Cuatro comedias difícilmente pasaría inadvertida; menos aún para Lope, ya veremos por qué.

Reconozcamos no obstante que, aun cuando el rastro gongorino sea bien patente, una y otra obra "comparten relativamente pocos elementos» (McGrady 2010: 18). El primero en atisbarlos fue Jammes (1967: 498), que descubrió ciertas analogías en torno a Lelio, mercader y uno de los galanes protagonistas de Las firmezas de Isabela, y el también mercader Hipólito, que en Virtud, pobreza y mujer presta su ayuda para que Isabel pueda rescatar al cautivo Carlos. En síntesis, ambos personajes comparten oficio, origen sevillano y el común amartelamiento por una dama llamada Isabel(a) en la ciudad de Toledo, donde también requiere sus amores una mujer de nombre Violante. A su vez, McGrady (2010: 18) advierte que algunos detalles de la trama de don Carlos en el primer acto (su intento de seducir a Isabel mediante una cédula de casamiento, por un lado, y el asesinato de otro galán, por otro) son similares a los que se cuentan, en forma de relato, acerca de Marcelo en Las firmezas de Isabela (vv. 588-635), ${ }^{7}$ que ha llegado a Toledo huyendo de sus perseguidores tras haber cometido, en efecto, tropelías equiparables a las de don Carlos. Finalmente, la crítica ha destacado, más bien de pasada, que en las dos obras se nos brinda una larga evocación de la historia y la belleza suntuosa de Toledo. Comoquiera que Lope era muy dado a prodigar generosos elogios y vastas descripciones de las ciudades en que transcurren sus comedias, y puesto que no se observan coincidencias reseñables al respecto entre Las firmezas de Isabela y Virtud, pobreza y mujer, podemos pasar de puntillas por tales versos; pero no sin antes recordar — lo vio muy bien Dolfi (1983: 280)— que tanto Góngora como Lope apuestan por una «dualità di voci» (Emilio y Galeazo; don Juan e Hipólito) para ensalzar la portentosa ciudad imperial.

Por otro lado, la insólita condición de Hipólito en el conjunto de la obra de Lope, en cuanto mercader con un papel fundamentalmente benigno, ${ }^{8}$ se ha explicado en parte como posible consecuencia del influjo de Las firmezas de Isabela (Jammes 1967: 498), pieza con un protagonismo destacadísimo de los mercaderes. ${ }^{9}$ Sin embargo, en la naturaleza de este personaje debió de influir

7. Los versos y las citas de Las firmezas de Isabela proceden siempre de la edición de Laura Dolfi, consignada en la bibliografía.

8. Aunque en un primer momento se muestra inclinado al juego e incluso planea forzar a Isabel, luego decide socorrerla y viajar con ella hasta Berbería, lo que permite el final feliz. Hipólito, de hecho, «amén de poseer una serie de cualidades hace el papel de Providencia, pues posibilita la realización del matrimonio, salva la situación económica, valora la virtud y otorga el perdón a su enemigo» (Campbell 1996: 114).

9. Sobre la figura del mercader en Las firmezas de Isabela y en otras comedias del Siglo de Oro, 
también la fuente principal de Virtud, pobreza y mujer, o sea, una novella de Masuccio (o, quizá, la versión de la misma debida a Granucci), dado que en ella el protagonista, Giovanni Piombino, es asimismo un mercader. De este modo, a mi juicio lo más probable es que el tan inusitado Hipólito sea el resultado de la conjunción de ambas fuentes, por mucho que la condición de amante cautivo encarnada por Piombino recuerde más a don Carlos que a Hipólito (lo que, unido a las correspondencias entre este último y el Lelio gongorino, permitiría en efecto emparentar al mercader lopesco con Las firmezas de Isabela). Al fin y al cabo, no deja de ser revelador que las dos únicas piezas de Lope que presentan a un mercader con un papel protagónico y positivo (Virtud, pobreza y mujer y El anzuelo de Fenisa) tengan su abrevadero principal en sendas novelle, como nos recuerdan McGrady (2010: 17) y Di Pastena (2018: 131). ${ }^{10}$

Ahora bien, sin negar que la comedia de Lope esté «visiblemente influida por la de Góngora» (Jammes 1984: 24), lo cierto es que estas semejanzas, trazadas en abstracto, pueden resultar algo engañosas, porque las circunstancias concretas en las que se desarrollan todos estos episodios compartidos resultan muy distintas, como se deduce enseguida al echar un vistazo a sendos argumentos. ${ }^{11}$ Por poner solo un par de ejemplos, la Violante de Virtud, pobreza y mujer es una prostituta, que como tal requiere los favores del mercader Hipólito y de muchos otros personajes, mientras que Violante, una de las damas de Las firmezas de Isabela, solo requiebra a Lelio momentáneamente en una escena en la que se produce un «trueque de las parejas» (Dolfi 2016: 227). Por otro lado, el asesinato cometido a manos de don Carlos en Virtud, pobreza y mujer es consecuencia de una riña que estalla cuando varios galanes se rifan una cadenilla para Violante; en Las firmezas de Isabela, en cambio, Marcelo acabó con la vida de un competidor que «quiso embestille una noche» (v. 605). Con todo, vale la pena reparar en que los tales paralelismos se concentran en el primer acto de Virtud, pobreza y mujer, un detalle muy significativo y en el que habremos de insistir.

Tirando del hilo de las semejanzas y divergencias, McGrady (2010: 18-19) recalcó el papel dispar de los protagonistas. Así, mientras que la Isabel de Lope se muestra "sumamente proba y casta», el comportamiento de Isabela es honesto

véanse Ferrer Valls (2018) y Roncero López (2018); para el caso de Lope, acúdase a Campbell (1992 y 1996).

10. Y ello a pesar de que, como muy bien explica Joan Oleza (2018: 297), en las comedias de inspiración italiana Lope suele borrar o atenuar el papel de los mercaderes y del entorno social burgués. A Virtud, pobreza y mujer y El anzuelo de Fenisa, Oleza (2018: 297) ha añadido recientemente El hijo de los leones, aunque el propio estudioso puntualiza que "el argumento no se desarrolla en un marco urbano contemporáneo sino en la Alejandría clásica”, por lo que el papel social del mercader no puede estudiarse en los mismos términos que en los demás casos.

11. El paciente lector dispone de excelentes resúmenes de Las firmezas de Isabela de la mano de Jammes (1984: 10-15) y McGrady (2010: 13); para Virtud, pobreza y mujer, cuenta asimismo con la sinopsis de McGrady (2010: 201-204), así como con el resumen correspondiente en la base de datos Artelope. 
en lo que concierne a sus demás pretendientes, pero su ardor por Lelio es tal que este llega a arredrarse y a temer por la integridad moral de la dama, en claro contraste con el galán de Lope, que no ceja en su empeño de poseer a Isabel. Así las cosas, McGrady (2010: 19) concluye que Lope habría invertido irónicamente el carácter de los protagonistas gongorinos. De nuevo, no obstante, la trama y la actuación de los personajes son tan distintas (basta con hojear sus argumentos) que tales conclusiones deben manejarse con suma precaución. Ahondaremos en el carácter y en la genealogía de Isabel.

Además de rastrear estas posibles huellas argumentales, Jammes (1967: 498) se fijó en la dedicatoria que antepuso Lope a Virtud, pobreza y mujer al publicarla en la Parte XX de sus comedias; una dedicatoria en la que el Fénix cita a Lope de Rueda y a Navarro, ${ }^{12}$ lo mismo que Góngora en su pieza (vv. 3229 y 3393), y en la que arremete contra los oscuros y artificiosos culteranos, lo que acaso podría ser un indicio de que en 1625, cuando la incluyó en la Parte XX, todavía "asociaba esta comedia suya con Góngora» (McGrady 2010: 18), tal y como ya supusiera Jammes (1967: 498). Creo que ambos estudiosos llevan razón. Sin embargo, no se trata de coincidencias tan significativas como pudiera parecer a simple vista, puesto que Lope aprovechó más de una dedicatoria para dejar recados a los cultos, sin ir más lejos en Lo cierto por lo dudoso o El marido más firme (también publicadas en la Parte $X X$ ), en las que esgrime argumentos muy similares al respecto (Case 1975: 244), sumido como estaba entonces —en 1624, cuando andaría preparando la impresión de la Parte — en plena polémica con Diego de Colmenares a propósito de la nueva poesía, a cuyos ataques parece aludir Lope en la dedicatoria de Virtud, pobreza y mujer..$^{13}$ Además, la mención conjunta de Rueda y Navarro (a los que Lope cita por separado en otros lugares $)^{14}$ entre los padres de la comedia nueva era habitual: a la célebre pareja se

12. «En España no se guarda el arte, ya no por ignorancia, pues sus primeros inventores, Rueda y Navarro, le guardaban, que apenas ha ochenta años que pasaron, sino por seguir el estilo mal introducido de los que les sucedieron» (Virtud, pobreza y mujer, ed. D. Fernández Rodríguez, pp. 402-403; las citas procederán siempre de esta edición). Debido a la desafortunada enmienda de Hartzenbusch (por lo demás siempre tan brillante en sus ediciones), tanto Jammes (1967: 498) como McGrady (2010: 37) leen «Naharro», pero no hay razón alguna para desechar la lección "Navarro»: Lope se refiere al comediante toledano Pedro Navarro, tal y como explica, en su excelente edición de la dedicatoria, Antonucci (2013), quien justifica su interpretación con varios pasajes similares que enseguida abordaremos. En cambio, en Las firmezas de Isabela, Góngora sí cita tanto a Torres Naharro como a Navarro (en posición de rima, por cierto): «Digo que Torres Naharro / no compuso tal comedia. / Emilıo Bien mi daño se remedia. / Octavio ¿̨Representó así Navarro?» (vv. 3390-3393).

13. Véase el comentario de Fausta Antonucci (2013) en su edición de la dedicatoria, así como las páginas de la propia Antonucci (2014) y de d'Artois (2014). Acerca de la polémica entre Lope y Diego de Colmenares, es imprescindible la consulta de Tubau (2007).

14. Así, en el Arte nuevo, el Fénix menciona a Lope de Rueda entre los garantes de una fórmula dramática más clásica que la suya («Lope de Rueda fue en Espańa ejemplo / de estos preceptos», ed. F. B. Pedraza Jiménez y P. Conde Parrado, vv. 64-65). En lo que atañe a Navarro, coetáneo 
la había visto pasearse de la mano en el Viaje entretenido de Rojas Villandrando (1603), en la Tercera parte del Confesionario (1610) de fray Juan González de Critana y en el estupendo prólogo a las Ocho comedias (1615) cervantinas. ${ }^{15} \mathrm{De}$ nuevo: volveremos sobre todo ello.

McGrady (2010: 18), que ha escudrińado los textos con suma pericia, añade otras coincidencias de mayor detalle, cuyo valor y trascendencia me propongo desentrañar acto seguido. Consiste la primera de ellas en un juego paronomástico entre las olas del mar y la expresión Hola (muy usada entonces para llamar a los criados e inferiores), por un lado, y el adjetivo oleado ('ungido con el óleo de la extremaunción'), por otro. El pasaje de Las firmezas de Isabela que nos incumbe es el siguiente:

\begin{tabular}{|c|c|}
\hline FABIO & Hola, Tadeo, ¿dó estás? \\
\hline TADEO & Parece que oigo a mi amo. \\
\hline FABIO & Hola, Tadeo, ¿̇a quién llamo? \\
\hline TADEO & $\begin{array}{l}\text { Sube arriba y lo sabrás. } \\
\text { Las olas te habrán echado } \\
\text { como a Leandro. }\end{array}$ \\
\hline $\mathrm{BIO}$ & Por cierto \\
\hline 0 & No fuera mal oleado. \\
\hline
\end{tabular}

(vv. 1835-1842)

En su edición, Dolfi (2016: 169) aclara cómo «Tadeo replica de manera impertinente que su amo lo ha llamado tanto que ha arriesgado, como Leandro, quedar sumergido por sus hola / olas», burla que se amplía con la posterior irrupción del adjetivo oleado, referido al muerto anterior, pero empleado también en relación a la muerte aciaga de Leandro entre las olas. En cuanto a Virtud, pobre$z a$ y mujer, el chiste se presenta en la escena en la que Isabel y Julio tratan en vano de recabar limosnas suficientes para pagar el rescate de Carlos:

Fabio Señora, Dios os provea.
Llevá ese caballo. ¡Hola!

Vase

Julio ¡Oleado estés, borracho, plega a Dios, antes de un hora!

(vv. 1565-1568)

del batihoja, Lope le cita en La cortesía de España (ed. E. Di Pinto, v. 2148) y en el «Prólogo dialogístico» de la Parte XVI (coord. F. d'Artois y L. Giuliani, p. 50).

15. Remito a Pedraza Jiménez y Conde Parrado (2016: 143-145). 
El criado Julio maldice a un galán que, tras mucho interesarse por Isabel, se limita a despedirse con un "Dios os provea», fórmula con la que uno fiaba a Dios el amparo del destinatario y se desentendía así de los pordioseros. El adjetivo oleado se explica aquí no solo por el último verso pronunciado por el galán, sino también por su primera intervención («iHola! Llevame el caballo», v. 1547), en la que se dirigía a sus criados con ese Hola tan característico, que cierra así, a modo de espejo, su brevísima aparición (vv. 1547-1566), rematada con el chistoso oleado que tan bien conocemos ya.

Para nuestros intereses, más que el juego entre los homónimos hola y ola, harto frecuente en la literatura española del Siglo de Oro y por tanto poco relevante, ${ }^{16}$ nos concierne el vínculo paronomástico entre hola y oleado, presente en ambas comedias y en otros textos de la época (era muy querido por Tirso, verbigracia), ${ }^{17}$ pero que al parecer no es tan común en Lope. Este de $E l$ gran duque de Moscovia y Emperador perseguido es el único ejemplo que he podido entresacar de su obra: «iHola, pajes! ¡Pajes, hola! / Rufino ¿Qué sirve tanto holear? / Aunque estuviera oleado, / me lo había de comer» (ed. M. Villar, vv. 1935-1938). A falta de que futuras investigaciones den con otros especímenes parejos, se trata de un caso importante, porque Lope debió de escribir El gran duque de Moscovia en $1608,{ }^{18}$ lo cual revela que ya había abonado la gracieta antes de que Góngora rematase su obra. Nada impide, claro está, que Las firmezas de Isabela pudiera azuzar su uso en Virtud, pobreza $y$ mujer, pero su presencia previa en manos del Fénix sin duda matiza su valor como indicio a favor del influjo de la pieza gongorina. Por lo demás, no creo que haya que dar demasiado crédito a la coincidencia onomástica entre los dos personajes — ambos se llaman Fabio_ que, con sus reiterados Hola, provocan el chiste en boca de Tadeo y Julio, aunque sin duda cabe ańadirla a las consignadas por McGrady (2010: 18).

A la zaga de «la imagen de la roca combatida por las olas como símbolo de la castidad defendida», que se cuela en ambas comedias, pero que se antoja muy «corriente» como para suponerle mayor trascendencia, McGrady (2010: 18)

16. Al respecto, es esencial consultar el breve y exquisito estudio de Prieto García-Seco (2020). En Lope hay constancia de esta homonimia ya en comedias tempranas, como El castigo del discreto (cuya fecha es dudosa, pero que en cualquier caso es anterior a la de Las firmezas de Isabela; véase Di Pastena y Poggi 2008: 203): "que algunas veces me holeas, / que no respondo y te enojas, / que las holas que me arrojas / no hay mar donde tantas veas» (ed. E. Di Pastena y G. Poggi, vv. 631-634). Para este y otros ejemplos en Lope, véase Fichter (1925: 220).

17. Uno de los más divertidos pertenece al Entremés de los enfados de Quevedo: «Hola acá y hola allá y holas y holillas, / y viendo a mis crïados / siempre tan holeados, / me llaman propiamente / El Caballero Extremaunción la gente» (cito por Prieto García-Seco 2020). El Teso permite rescatar varios ejemplos en la obra de Tirso.

18. Largo y tendido se ha discutido la fecha de redacción de la comedia, tal y como documenta en el prólogo a su edición Villar (2008: 463-465), pero Iglesias Feijoo (2007) ha aportado argumentos muy sólidos para situarla en 1608. 
señala que en el mismo pasaje Góngora utiliza también, de nuevo como emblema de la castidad, la metáfora de la encina que resiste los embates del viento:

Encuentra el mar, estándose ella queda,
la roca, o levantada sea o robusta,
y sin moverse con el viento justa
la dura encina, honor de la arboleda:
tal quiero que suceda
con mi firmeza hoy, que determina
ser roca al mar y al viento ser encina.

(vv. 2139-2145)

En opinión de McGrady (2010: 18), la asociación de la encina a la defensa de la castidad constituye «un simbolismo nada tradicional que Lope adapta en "arrancar la más antigua encina"» (v. 480), verso que define atinadamente como «intentar lo más difícil» (McGrady 2010: 140), en alusión a la vana insistencia de Isabel, que le ruega a Carlos que abandone su casa y la deje al fin sola: «Dieron las diez, rogome que me fuera, / y era arrancar la más antigua encina» (vv. 479-480). Lo cierto no obstante es que Lope se refiere muy a menudo a la dureza y resistencia de las encinas, particularmente como metáfora de la entereza moral y amorosa: se trata de una imagen harto asentada en su lengua poética, conque no es imprescindible suponer un vínculo con Las firmezas de Isabela. Valgan como botón de muestra dos bellos sonetos, uno de ellos inserto en la temprana comedia El dómine Lucas (que, como Las firmezas de Isabela, enlaza la indomable encina con la roca marítima ${ }^{19}$ y otro perteneciente a las Rimas: «Si la más dura encina que ha nacido / del corazón de la Morena Sierra / o el Alpe en su nevada cumbre encierra, / fiero desdén, te hubiera producido...». ${ }^{20} \mathrm{De}$ hecho, incluso la adjetivación de la encina como antigua es lopesca por los cuatro costados: "Montañas heladas / y soberbios riscos, / antiguas encinas / y robustos pinos...» (Peribáñez, ed. A. Blecua y G. Salvador, vv. 146-149); «mas la muchacha está rebelde y dura, / como está a la segur la vieja encina, / ni ruegos ni amenazas aprovechan» (El principe despeñado, ed. A. Pozo y G. Serés, vv. 921923). Así pues, lo que resulta original en el tratamiento de la encina en Virtud, pobreza y mujer es que la metáfora se aplique a don Carlos — que no ceja en su empeño de gozar de Isabel y al que no hay modo de arrancar de casa de la joven-y no, como sería previsible, a la protagonista, cuya firmeza no deja de ponderarse en todo momento. ¿Quiere ello decir que Las firmezas de Isabela no pudiera avivar la imagen en la mente de Lope? Desde luego que no: la roca y la

19. «No es tan robusta sobre el alta sierra / la vieja encina, ni en la mar salada / la roca de los vientos contrastada, / opuesta siempre a su furiosa guerra» (El dómine Lucas, ed. M. M. GarcíaBermejo Giner, vv. 2165-2168).

20. Se trata del soneto CLIII de las Rimas. Cito por la edición de Felipe Pedraza (1993: 519). 
encina incontrastables echan el cierre al segundo acto de la pieza gongorina, una posición que les aseguraría una cierta resonancia en la memoria literaria de cualquier lector que se acercara a sus versos, y más aún en la de todo un especialista en el arte de la reescritura.

Mucho menos significativo me parece otro de los detalles que McGrady (2010: 141) juzga común a ambas comedias, esto es, «un conocido chiste que afirma que a una mujer le da miedo dormir sola». En Las firmezas de Isabela, tal burla asoma la nariz a la par que el criado Tadeo, quien comenta en aparte que «Entrará a quitalla el miedo» (v. 145), una respuesta jocosa al ruego que su amo, Fabio, dirige a Marcelo para que este se quede en casa con Violante: «Tadeo, ven al instante, / y vos entraos con Violante» (vv. 143-144). En Virtud, pobreza y mujer, en cambio, la alusión a ese supuesto chiste acerca del temor de las mujeres a dormir solas se produce cuando Carlos y Julio están a punto de llamar a casa de la Violante lopesca, una prostituta, y de pronto la ven aparecer junto a varios galanes, conque no pueden por menos que exclamar: "CARLOs No gusta de estar sola. Julio Temor tiene» (v. 556). El contexto es radicalmente distinto y, además, en este último caso las palabras de Julio no parecen reflejar el "conocido chiste» al que alude McGrady (2010: 141); ${ }^{21}$ se trata más bien de una referencia jocosa al hecho de que Violante, como buena meretriz, prefiere estar siempre rodeada de solícitos clientes. ${ }^{22}$ Es más, tales comentarios no dejan de ser algo vagos, y remiten de manera general a la cobardía y al temor tradicionalmente asociados al carácter femenino. El vínculo entre ambas escenas es, para qué negarlo, endeble.

Examinados ya todos los paralelismos (onomásticos, argumentales, estilísticos) entre una y otra obra, es hora de abordar las circunstancias históricas y polémicas que envolvieron su escritura y publicación, imprescindibles para aquilatar el parentesco. A juzgar por la fecha del manuscrito Chacón, Góngora escribió su comedia en 1610, es decir, tan solo un año después de que Lope publicara su Arte nuevo, cuya lección fundamental, el necesario sacrificio de los preceptos clásicos en el altar del gusto popular, quedaba decididamente relegada en el teatro del cordobés, debido al «respeto absoluto que, yendo en contra de las nuevas costumbres teatrales, don Luis guardó a aquellas unidades de tiempo y de lugar de las que el Fénix se había despegado tan claramente» (Dolfi 2002: 37). Al abrigo de estas fechas, y al margen ahora de otros hallazgos y desafíos del teatro gongorino frente al lopesco — tan bien estudiados por Dolfi—, me limitaré a recordar el reciente juicio de Florence d'Artois, que ha incidido en varias facetas de Las firmezas de Isabe-

21. Presunto chistecillo del que McGrady (2010: 178) no da más pistas, pero que asegura advertir también en el siguiente pasaje de una de las novelas en verso de Cristóbal de Tamariz: «Otro dolor mayor y más cresido / le aprieta agora, y es un cierto espanto, / que como duerme sola, la cuitada / anda de ciertos duendes asombrada» (ed. D. McGrady, p. 326). Tampoco aquí acierto a observar la presencia de ningún chiste concreto que pase de un texto a otro.

22. Como, por lo demás, reconoce el propio McGrady (2010: 141). 
la que sin duda buscaban rivalizar con la fórmula de Lope: el respeto de las unidades aristotélicas en el seno de una intriga sumamente compleja, la evocación de modelos como Lope de Rueda, Navarro y Torres Naharro frente al Fénix ${ }^{23}$ y, finalmente, la elección de un género tan lopesco como la comedia de enredo, todo lo cual, por medio de un proceso de imitación y sublimación, «donne à la polémique des airs de duel» (d'Artois 2014: 100).

Otra circunstancia a mi parecer fundamental, pero sobre la que apenas se ha llamado la atención en las pocas ocasiones en que la crítica se ha planteado la relación entre Virtud, pobreza y mujer y Las firmezas de Isabela, es que la pieza gongorina se incluyó en el volumen titulado Cuatro comedias de diversos autores (Córdoba, Francisco de Cea, 1613), nada menos que al frente de una obra de Lope, La comedia de los Jacintos y celoso de si mismo, ${ }^{24}$ a la que seguían dos piezas de autoría dudosa, pero atribuidas al Fénix con más o menos garantías (El lacayo fingido y Las burlas y enredos de Benito). ${ }^{25}$ Desde luego, resulta difícil imaginar que Lope no le hincara el diente a la comedia de su rival, más aún en unas condiciones tan caprichosas: justamente en 1613, cuando se empezaron a difundir las Soledades en Madrid y las pugnas entre Lope y los cultos alzaban el vuelo, ${ }^{26}$ resulta que un volumen concebido de espaldas al Fénix reunía sus versos junto a los de su adversario poético y, todo hay que decirlo, dramaturgo advenedizo. La polémica, y en nuestro caso la reescritura, estaba servida. ${ }^{27}$

En efecto, a la vista de los indicios textuales y del contexto histórico, lo más probable es que Lope tuviera muy presente Las firmezas de Isabela, aun cuando se trate efectivamente de una «fuente menor», comoquiera que su influjo en Virtud, pobreza y mujer se reduce a "unos cuantos detalles» (McGrady 2010: 11). A mi juicio, el análisis emprendido aquí confirma las sospechas de Jammes (1967: 498): «Je crois plutôt pour ma part que, lorsqu'il écrivait sa pièce, Lope avait lu ou relu depuis peu celle de Góngora et que, sur ces souvenirs, sa fantaisie a brodé librement».

En cambio, me parece un poco arriesgado suponer que tras la obra de Lope subyazca necesariamente una intención paródica forjada en la inversión de la

23. "Il s'agit d'effacer le geste novateur de Lope dans l'Arte nuevo, de nier la place qu'il s'était octroyée dans ce même texte dans la généalogie du théâtre national, et de lui opposer des modèles plus respectueux de l'art» (d'Artois 2014: 100).

24. La comedia, que ahora puede leerse en la edición de Paula Casariego (2019), es más conocida como La pastoral de Jacinto.

25. Sobre la atribución de El lacayo fingido a Lope, véanse Arjona (1954), Morley y Bruerton (1968: 82) y Smyth (1982); para el caso de Las burlas y enredos de Benito, Arjona (1960) y Morley y Bruerton (1968: 426).

26. Por su especial relación con Lope y las fechas que nos ocupan, remito a los trabajos de Osuna Cabezas (2008), López Bueno (2011), Cacho Casal (2012), Blanco (2013) y García-Reidy (2015). 27. Para más inri, al poco de que Lope rematara Virtud, pobreza y mujer en 1616, Las firmezas de Isabela y las otras tres piezas se publicaron de nuevo juntas en Cuatro comedias famosas de don Luis de Góngora y Lope de Vega Carpio (Madrid, a costa de Juan Berrillo, 1617). 
actitud de sus protagonistas (el timorato Lelio convertido en el decidido don Carlos, la apasionada Isabela vuelta en la casta Isabel, digamos), que es una de las hipótesis que maneja McGrady (2010: 21): ello implicaría simplificar en exceso ambas tramas, obviar los muy dispares vericuetos argumentales que recorre Virtud, pobreza y mujer (mucho más cerca de su fuente italiana que de la gongorina) y, en definitiva, conceder a Las firmezas de Isabela un protagonismo tal vez algo excesivo en la concepción de Virtud, pobreza y mujer - matizaré este aspecto en lo que se refiere al carácter de Isabel-, aun cuando, como digo, sus huellas sean patentes. Lope, me parece a mí, quiso hacer otra cosa.

No en vano, Virtud, pobreza y mujer se explica mucho mejor sobre la falsilla del género bizantino (con sus raptos, viajes y cautiverios) y la novela italiana, un campo ya explorado en varias ocasiones por el Fénix, ${ }^{28}$ y también al arrimo de un trasfondo moral y ejemplar — exhibido ya desde el propio título-, gracias sobre todo a la integridad de Isabel, pero, también, al arrepentimiento de don Carlos y al cambio de actitud de Hipólito (quien, a punto de forzar a la protagonista, decide ayudarla a rescatar a su amado contrito). Apuesta esta última muy del agrado del público, como reconoce el propio Lope en el Arte nuevo tras haber ponderado «los casos de la honra»: «Con ellos, las acciones virtuosas: / que la virtud es dondequiera amada, / pues que vemos, si acaso un recitante / hace un traidor, es tan odioso a todos / que lo que va a comprar no se lo venden, / y huye el vulgo de él cuando le encuentra; / y si es leal, le prestan y convidan, / y hasta los principales le honran y aman, / le buscan, le regalan y le aclaman». ${ }^{29}$

Con todo, de acuerdo con la práctica de la imitatio multiplex, a la hora de escribir una comedia Lope solía fundir distintas voces, ecos y recuerdos; en este caso, se diría que Las firmezas de Isabela le vino a las mil maravillas para urdir ciertos detalles de la trama: mientras que el influjo de la historia relatada por Masuccio y retomada por Granucci (y, con ella, el ajetreo bizantino entre corsarios y cautivos) está mucho más presente en el devenir general de la obra, recordemos que los paralelismos argumentales con Las firmezas de Isabela se concentran en el primer acto de Virtud, pobreza y mujer. Pues bien, resulta que, en ese primer acto, la huella de la novella aún no es tan acusada, dado que en él no se producen aún los incidentes fundamentales del periplo bizantino que hermanan la comedia con la novela (el rapto del protagonista, el fracasado intento de reunir el rescate, la decisión de la dama de venderse como esclava, etc.). Como en tantas otras ocasiones, ${ }^{30}$ para encauzar la trama de Virtud, pobreza y mujer Lope se vale de distintos veneros, cada uno de los cuales abastece con mayor vigor momentos sucesivos: Las firmezas de

28. Pueden verse casos parecidos en Fernández Rodríguez (2019b).

29. Cito por la magnífica edición de F. B. Pedraza Jiménez y P. Conde Parrado, vv. 329-337.

30. Sin ir más lejos, en otra comedia bizantina de raigambre italiana, La viuda, casada y doncella (por ceñirme a un ejemplo similar en términos genéricos y genealógicos), Lope privilegia cada una de sus fuentes en momentos sucesivos de la trama (Fernández Rodríguez 2018a). 
Isabela se deja sentir ante todo (y solo de refilón) en el primer acto; la novella, en el resto de la obra. De ahí que, en rigor, tal y como ya concluyese Jammes (1967: 500) pese a admitir como tales parte de las deudas y reminiscencias aquí examinadas y pese a ignorar la fuente masucciana, quizá no sea pertinente concebir Las firmezas de Isabela — al contrario que la novella — como un modelo de Virtud, pobreza y mujer, sino más bien como un punto de partida. ${ }^{31}$

Pero no seamos ingenuos. En su artículo, tan perspicaz, d'Artois (2014: 102) explica a la perfección cómo «la reprise de certains éléments de la pièce gongorine, même superficiels, indique un dialogue avec cette dernière, qui vise à opposer une poétique à une autre. S'il n'y a pas réécriture stricte, il y a donc bien intention polémique». En efecto, Lope sabía muy bien lo que hacía y con quién se las gastaba. No obstante, la hipótesis polemista, brillantemente defendida por d'Artois (2014: 102), topaba hasta ahora con «le problème de la datation incertaine de la comedia», que, ya lo sabemos, por fin se ha podido resolver: pues bien, la fecha de 1616 nos sitúa en pleno apogeo de la polémica entre Lope y los cultos, ${ }^{32}$ lo que a su vez debe avivar nuestras sospechas ante las analogías entre Virtud, pobreza y mujer y Las firmezas de Isabela, que serían de todo menos inocentes; aunque, insistimos una vez más, en lo que concierne al carácter de los personajes y al proyecto global de la pieza no conviene orillar los diversos graneros - tanto o más fecundos que la comedia de Isabela - en los que Lope se abasteció: el género bizantino, una novella italiana y las beneméritas y siempre bienvenidas «acciones virtuosas».

Años después, cuando Lope decidió incluir Virtud, pobreza y mujer en la Parte XX (1625) y dedicar la comedia a Giambattista Marino, no pudo o no quiso refrenar sus impulsos y arrojó otro dardo envenenado a Góngora y los suyos. En efecto, tal y como ha estudiado la propia d'Artois (2014: 103-107), uno de los objetivos principales de la dedicatoria a Marino es lanzar una pulla contra los culteranos; y no solo por las críticas explícitas a la nueva poesía (áspera, artificiosa y arrogante), ${ }^{33}$ sino también porque el elogio del napolitano en los

31. El juicio de Jammes (1967: 500), que transcribo íntegro por su clarividencia, parte del análisis comparado de Las firmezas de Isabela y El mercader amante de Gaspar de Aguilar: «Les points de contact entre la pièce de Góngora et celle d'Aguilar ne se limitent donc pas au contenu, on les trouve aussi sur le plan de la forme. Mais les différences sont encore plus nombreuses et plus substantielles, ce qui exclut toute hypothèse d'imitation directe et consciente ; Aguilar n'a pas servi de modèle à Góngora, pas plus que Góngora n'a servi de modèle à Lope. Disons seulement que, dans la mesure où le processus initial de la création artistique est toujours déclenché par un certain nombre de causes difficiles à déceler et à évaluer, il parait vraisemblable que El mercader amante ait amené Góngora à écrire Las firmezas de Isabela, qui a pu, à son tour, être le point de départ de Virtud, pobreza y mujer de Lope».

32. "Estamos en los años más enconados de la polémica, tal vez los peores de la carrera de Lope», nos cuenta Antonio Sánchez Jiménez (2018: 259) en su Lope. El verso y la vida.

33. Así la despacha Lope —el desquite no tiene desperdicio- a propósito del octosílabo («los versos cortos son castellanos antiguos»...): «dulce y dificultosa composición, que la falta del natu- 
términos que prodiga Lope presupone una defensa de su propia posición en la polémica gongorina: por un lado, semejante alabanza puede entenderse como el ensalzamiento de un modelo alternativo de fábula mitológica y pastoril frente al Polifemo y las Soledades, ${ }^{34}$ por otro, la abundante producción y la variedad de estilos cultivados por Marino, que Lope reivindica en esta y en la dedicatoria de El marido más firme, ${ }^{35}$ incluida asimismo en la Parte $X X$, permiten trazar un vínculo evidente entre la fertilidad creativa de Marino y la del madrileńo, tan criticada por Góngora y compañía (Antonucci 2014: 92-94).

Por ahí, quizá ahora podamos leer en una clave algo distinta la siguiente aseveración de Lope, embutida justo antes de arremeter contra los cultos: «En Espańa no se guarda el arte, ya no por ignorancia, pues sus primeros inventores, Rueda y Navarro, le guardaban, que apenas ha ochenta años que pasaron, sino por seguir el estilo mal introducido de los que les sucedieron». Lope se cura en salud ante Marino y "previene posibles objeciones sobre la falta de respeto a las reglas llamadas aristotélicas, previsibles en un hombre que procede de un ambiente cultural, el italiano, que había sido la cuna del neoaristotelismo» (Antonucci 2013), para lo cual excusa esa libertad de la comedia nueva y de su propia fórmula dramática no en la ignorancia de los preceptos (el arte), sino en la necesidad de seguir el camino emprendido por dramaturgos anteriores, tal y como ya había hecho en el Arte nuevo. ${ }^{36}$ Es cierto que la mención de Rueda y Navarro como padres del teatro no dejaba de tener un aire algo tópico - así lo hemos constatado- y es cierto también que en otros paratextos de la Parte $X X$ aprovecha Lope para arremeter contra los cultos y, a la vez, defender su propuesta

ral, que ha de ser el primero fundamento de este edificio, destierra con arrogancia, introduciendo en España la bárbara aspereza que llaman culta, por quien la defensa de la lengua (cuya gramática no sufre estas novedades) me debe tantas injurias» (Virtud, pobreza y mujer, pp. 403-404).

34. «Dans cette dédicace qui date de 1624, Lope joue ainsi sur la nouveauté de l'Adone dont la publication était probablement encore trop récente pour qu'il ne soit entaché par les critiques de ses censeurs italiens, pour essayer de détrôner le Góngora du Polifemo et des Soledades en lui opposant le foisonnement, la variété, et la douceur de la poésie de Marino, qu'il utilise comme une projection idéale de la sienne» (d'Artois 2014: 107).

35. «Y siendo Vuestra Señoría en su profesión tan único que los bien nacidos ingenios le conceden el primero lugar en toda Italia, y nuestros españoles leen con venerable admiración la inmensa copia de sus escritos en tantas Rimas sacras y humanas, ¿quién duda que puede calificar su alabanza, graduar su estimación y defender su juicio?» (Virtud, pobreza y mujer, p. 397); «Todo lo que he visto de Vuestra Merced [Manuel de Faria e Sousa], así en prosa como en verso, muestra bien la fertilidad de su claro juicio, que la abundancia, que algunos desestiman, a mí me persuade con el ejemplo de los campos, que el concierto breve de los cultivados jardines es inferior a la inmensa copia de la naturaleza, que en su variedad ha puesto su hermosura [...]. Escriba Vuestra Merced con fertilidad libros, canciones, fábulas, epitalamios, a imitación del abundante, insigne, dulce, heroico, grave y amoroso caballero Juan Bautista Marino, honrando y dilatando su lengua y la nuestra» (El marido más firme, ed. C. Monzó Ribes, pp. 922-923).

36. "Arte de hacer comedias en Espańa, / donde cuanto se escribe es contra el arte»; «Mas pues del arte vamos tan remotos / y en España le hacemos mil agravios» (ed. F. B. Pedraza Jiménez y P. Conde Parrado, vv. 134-135 y 171-172). 
dramática (Antonucci 2014: 84), ${ }^{37}$ por lo que tal vez no convendría exagerar el alcance —en lo que se refiere al vínculo entre Las firmezas de Isabela y Virtud, pobreza y mujer - de la conjunción entre las reivindicaciones teatrales y las poéticas (o, si se quiere, lingüísticas). Sin embargo, a la luz del carácter polémico de la dedicatoria y de la evocación de Lope de Rueda y Navarro, citados en Las firmezas de Isabela como «ideal dramático» (Jammes 1984: 22), es posible que estemos ante otro recuerdo de la rencilla teatral entre Lope y Góngora (d'Artois 2014: 104), esto es, ante otro indicio de la relación entre las virtudes y firmezas de Isabela e Isabel. Con todo lo que sabemos ahora, no parece casual que en 1624, al ultimar la Parte XX, se parapetara Lope con Virtud, pobreza y mujer para cubrirse las espaldas ante sus detractores $y$, sobre todo, para acometer de nuevo a su eterno rival; más allá del contexto inmediato de las polémicas en los primeros ańos veinte ${ }^{38} \mathrm{y}$ de todas las razones que tan a menudo les llevaron a enzarzarse en disputas de diverso pelaje, en este caso parece que la alargada sombra de Isabela pudo proyectarse también sobre la dedicatoria. Lope cerraba así un capítulo fascinante de su rivalidad, ahora también teatral, con Góngora. ${ }^{39}$ Una decisión que, hasta cierto punto, tal vez «éclaire rétrospectivement la conception» de Virtud, pobreza y mujer, al decir de d'Artois (2014: 103). Volvamos pues, ya para terminar, a los textos.

No parece entonces descabellado suponer, como McGrady (2010: 19), que en algún verso quisiera Lope juguetear con Las firmezas de Isabela y esparcir migajas de su título: "Premio los cielos te den, / Isabel, de esa firmeza» (vv. 2136-2137). Desde luego, Lope no rehuyó tal parentesco, comoquiera que hasta en cinco ocasiones denomina «Isabela» a su protagonista, aunque don Juan se apresure a recalcar que el modelo que explica y justifica el apodo - de puertas afuera cuando menos - no es sino el Orlando furioso: «que aunque se llama Isabel, / porque Arïosto celebra / una casta de este nombre / — de quien mil virtudes cuenta- / la llama Toledo ansí» (vv. 377-381). ¿Acaso otro recado para Góngora en forma de ostentoso olvido? Quien calla otorga: la cercanía cronológica entre la publicación de Las firmezas de Isabela y la composición de Virtud, pobreza y mujer permitiría a los más avispados —o maliciosos, que de todo habría - entrever un cierto aire de familia en ambas obras; los más distraídos o desmemoriados, ya lo vemos, contaban con pistas nada desdeñables.

Hay algo más. Un detalle que los estudiosos de Virtud, pobreza y mujer han pasado por alto, pero que resulta crucial para acabar de acrisolar la veta polemis-

37. A este respecto, resultan particularmente interesantes el final del breve paratexto inicial llamado "Títulos de las comedias y a quién van dedicadas» y, también, la dedicatoria a Lo cierto por lo dudoso (ed. S. Vuelta, pp. 309-316). Véanse los comentarios de Serés (2011: 231-232) y Antonucci (2014: 86-87).

38. Además de la bibliografía ya citada a este respecto en la nota 13, véase Conde Parrado (2019). 39. A decir verdad, Lope llevaba años dando la matraca desde las tablas contra el cordobés; Santiago Restrepo (2017) desmenuza un caso muy temprano (y esdrújulo). 
ta de la pieza. El segundo acto da comienzo con la visita de Feliciano, el tío de Isabel, que nos cuenta los desventurados avatares de la familia:

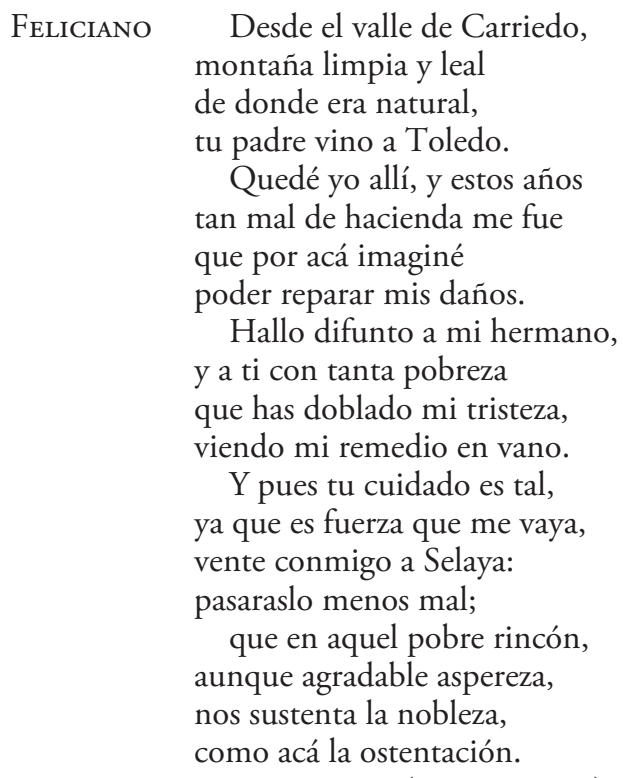

(vv. 999-1018)

Más allá de las obvias diferencias, que no hace al caso apurar, salta a la vista que la historia de la familia paterna de Isabel guarda notables similitudes con la ascendencia paterna de Lope: una y otra proceden del Valle de Carriedo, hermoso paraje cántabro de donde al parecer era natural el abuelo paterno del poeta, llamado también Lope de Vega, presuntamente oriundo de Vega de Carriedo, hoy Vega de Villafufre, municipio que habría dado nombre al apellido familiar; no era el caso del padre del dramaturgo, Félix o Felices de Vega, nacido en Castromocho, villa palentina en Tierra de Campos, aunque Lope — buena cuenta le traía- gustaba de resaltar su abolengo montañés (Sánchez Jiménez 2018: 37). De este modo, Félix o Felices de Vega (nótese el parecido onomástico con Feliciano, tío de la joven), de origen carredano y de profesión bordador (ocupación similar a la de Isabel), ${ }^{40}$ emigró a la gran ciudad, lo mismo que el padre de la protagonista (el

40. Lo acaba de recordar Isabel en la intervención inmediatamente anterior al pasaje citado («solo, señor, / me sustenta mi labor», vv. 996-997), en palabras casi idénticas a las que dirige a don Carlos en el primer acto: «que un padre honrado, perdido / por fianzas, y al fin muerto, / dejó este campo desierto, / de sus consejos florido, / donde solo mi labor / me sustenta, como sabes» (vv. 225-230). En el fallecimiento prematuro del padre — naturalmente en circunstancias muy distintas a Félix de Vega, afamado bordador- cabría entrever también un cierto eco autobiográfico, pues Lope perdió al suyo con apenas quince años. Para más detalles sobre el padre del dramaturgo, véase Sánchez Jiménez (2018: 38-39). 
primero a Valladolid y luego a Madrid; el segundo, a Toledo). No es esta la única ocasión en la que Lope, en boca de personajes cuyos nombres recuerdan al de su padre, esboza retazos pseudobiográficos en relación al valle de Carriedo: de hecho, otro tanto ocurre nada menos que en dos de las otras tres comedias en las que he hallado alusiones al mítico valle; los encargados de invocarlo son, qué sorpresa, un tal Feliciano en La venganza venturosa y un tal don Félix en Quien ama no haga fieros; ${ }^{41}$ en la primera obra, además, se menciona — como en el pasaje transcrito de la nuestra - el municipio de Selaya, pueblo del valle de Carriedo muy cercano a Vega de Villafufre y, para Lope, otro emblema de su Montaña querida:

[Feliciano] Diome el valle mejor de la Montaña
una torre, una casa solariega
que en pie miró la destruición de España
y hasta los tiempos de Filipo llega;
las heredades que un arroyo baña,
dehesa pobre entre Selaya y Vega,
fueron todo el caudal de mis mayores,
de algún rey, por ventura, sucesores.

(La venganza venturosa, ed. E. Calderwood, vv. 628-635)

A lo largo de su vida, el Fénix exageraría y reivindicaría su origen montañés para blasonar de sangre hidalga; uno de los testimonios más conocidos al respecto se encuentra en la epístola de "Belardo a Amarilis», impresa en La Filomena (1621), que nos permite constatar (lo mismo que la octava de La venganza venturosa) las similitudes con la saga familiar de Isabel, procedente del mismo solar cántabro, tan noble y linajudo como pobre de solemnidad:

Tiene su silla en la bordada alfombra de Castilla el valor de la Montańa que el valle de Carriedo España nombra.

Allí otro tiempo se cifraba España, allí tuve principio; mas ¿qué importa nacer laurel y ser humilde caña?

Falta dinero allí, la tierra es corta; vino mi padre del solar de Vega: así a los pobres la nobleza exhorta. ${ }^{42}$

«Las semejanzas entre el discurso de Feliciano y la epístola de "Belardo a Amarilis" apuntan hacia el juego autobiográfico que sustenta gran parte de la

41. «Don FéLIx Pon, Gastón, mi ropa presto, / esos papeles recoge, / saca esas maletas luego. / Hoy me parto a la Montańa. / Deme el valle de Carriedo / en sus suelos sepultura, / lloren mis padres...» (Quien ama no haga fieros, ed. P. Ruiz Pérez, vv. 1384-1390). La otra referencia al valle de Carriedo se encuentra en La serrana de Tormes (ed. E. Maggi, v. 740).

42. Cito por Sánchez Jiménez (2018: 36-37). 
obra de Lope». Son palabras de Calderwood (2010: 272) referidas a La venganza venturosa y a la octava antes transcrita; por supuesto, no pueden aplicarse sin más a nuestra comedia, pero sí nos ayudan a comprender que en Virtud, pobreza y mujer buscaba Lope, digámoslo así, emparentar con su Isabel: un guiño que los más allegados podrían reconocer fácilmente y que, en el contexto de la polémica y el vínculo con Las firmezas de Isabela, no parece en absoluto casual. Más difícil resulta calibrar el significado preciso de tal gesto; en cualquier caso, la genealogía de Isabel es otra muestra de que Lope quiso entrar al trapo y no se anduvo con miramientos a la hora de enfrentar a la Isabela gongorina su propia Isabel (y no pocas veces, Isabela), cuya virtud y nobleza de espíritu le permiten sortear mil y un obstáculos, particularmente esa pobreza exhibida desde el propio título. No hay por qué forzar el pretendido alcance autobiográfico: basta con reconocer que el desafío se presentaba en bandeja para cualquiera que estuviera mínimamente al tanto de la vida, obra y milagros de Lope de Vega y Luis de Góngora. O sea, para toda la parroquia literaria, amén de curiosos y advenedizos.

¿Hasta qué punto, entonces, la fisonomía de Virtud, pobreza y mujer obedece, siquiera ex contrario, a Las firmezas de Isabela? No es fácil decretar en qué medida, pero conviene ser muy precavidos, dadas las profundas divergencias argumentales y el parco influjo de la comedia gongorina frente a otros —estos sí- moldes y modelos. Desde luego, Virtud, pobreza y mujer rompe generosamente las unidades de tiempo y de lugar, gracias a una acción que transcurre a lo largo de más de ocho meses y que se desarrolla en diversas ciudades españolas y en el norte de África, todo lo contrario que la aristotelísima pieza gongorina..., pero al igual que otras tantas comedias lopescas, en particular las de cuño bizantino. ${ }^{43}$ Por otro lado, ¿se propuso Lope dar vida a una Isabel todavía más firme que Isabela, en una suerte de competencia con su rival? ¿Llevaba razón McGrady al postular que el Fénix quiso invertir el carácter tanto de Lelio como de Isabel? Preguntas así entrañan no poco riesgo y nos podrían arrastrar por los caminos, sin duda tentadores, de la especulación, conque haríamos bien en recordar, de nuevo, el papel secundario de Las firmezas de Isabela en la armazón textual de Virtud, pobreza y mujer (el leve rastro gongorino se percibe tan solo en el primer acto) frente al patrón bizantino y la novela de Masuccio, del mismo modo que no hay que perder de vista la inclinación del Fénix y del público por los casos virtuosos (tan ponderados en el Arte nuevo, insisto). Todo lo cual invita a manejar este tipo de interpretaciones con precaución, pues la hechura de Virtud, pobreza y mujer permite explicarse (salvo ciertos detalles de indudable sabor polémico a Isabela) desde sus propios presupuestos estéticos y tradiciones literarias, sin necesidad de acudir a Las firmezas de Isabela para explicar cualquiera de las numerosas diferencias que a cada paso las separan. Aunque, naturalmente, en vista de que el Fénix se preocupó de hacer de Isabel una portadora de

43. Al respecto, puede verse Fernández Rodríguez (2018b). 
sus propias vicisitudes biográficas (más o menos fantasiosas), resulta plausible que con su apabullante virtud quisiera Lope —el Lope polemista, según rezaba el atinado título de un congreso organizado por PROLOPE- desbancar a la Isabela gongorina; al fin y al cabo, muchos juzgarían a la criatura lopesca con un ojo puesto en su adversaria. Por ahí sí cabría dar la razón a McGrady, con toda la cautela que se quiera. ${ }^{44}$

Sea como fuere, la huella textual de Las firmezas de Isabela, circunscrita al primer acto de Virtud, pobreza y mujer (en las correspondencias en torno a Hipólito y Lelio y, en menor medida, entre don Carlos y Marcelo; en el papel positivo del mercader; y tal vez en el uso de ciertas metáforas y juegos de palabras, e incluso en el generoso elogio de Toledo), por modesta que sea y en los términos anteriormente expuestos, resulta evidente, lo mismo que el deseo de Lope de no escurrir el bulto y dar la cara, tanto a la hora de componer Virtud, pobreza y mujer (mediante ciertos ecos onomásticos, la evocación del título de la obra gongorina o las reminiscencias autobiográficas en Isabel) como de publicarla, encabezada por una dedicatoria polémica y anticultista, en la Parte XX de sus comedias. En plata: Lope no escatimó en pullas contra la pieza de su eterno rival, punto de arranque de la suya, sí, pero hija del cordobés al fin y al cabo, y fruto de una propuesta teatral que en buena medida suponía una reacción contra la favorita del público en los corrales y aposentos. La del Fénix de los Ingenios, quién si no.

44. En otro orden de cosas, estos aires de desafío podrían inducirnos a leer en clave ciertos versos o pasajes, un procedimiento tan goloso como arriesgado; a fin de sortear la tentación de las interpretaciones cabalísticas, me limitaré a advertir que el encendido recuerdo de Garcilaso en Virtud, pobreza y mujer, que asoma en la descripción lopesca de Toledo («mas pues en ella nació / Garcilaso de la Vega, / su espíritu resucite. / JuAN ¡Qué bien que pintó las ruedas / en sus églogas divinas, / por donde las aguas trepan / a competir con los olmos / que el Tajo dorado riega!», vv. 273-280), podría ser en parte una respuesta a un fragmento burlesco de Las firmezas de Isabela ( «¿Versicos de Garcilaso / en tus uñas? [...] / ¡Oh para mí, Isabela, más hermosa / que el prado por abril de flores lleno! / Guárdame los jazmines de tu seno / para mañana, que has de ser mi esposa», vv. 1478-1489), en el que se adaptan unos versos famosos de la Égloga III («Flérida, para mí dulce y sabrosa / más que la fruta del cercado ajeno, / más blanca que la leche y más hermosa / que el prado por abril de flores lleno", ed. B. Morros, vv. 305-308); a fin de cuentas, no otro es el poema en el que piensa don Juan en el pasaje transcrito de Virtud, pobreza y mujer («De allí con agradable mansedumbre / el Tajo va siguiendo su jornada / y regando los campos y arboledas / con artificio de las altas ruedas», ed. B. Morros, vv. 214-216). Por lo demás, la alabanza de Garcilaso en Virtud, pobreza y mujer resulta la mar de natural, dado que Lope, tal y como mandaban los cánones de la laus urbis, ensalza a los hijos ilustres de Toledo, en particular en el ámbito de las letras (el humanista Gregorio Hernández y los poetas Pedro Liñán y Pedro Laínez), conque diría que tampoco hay que llevar las cosas mucho más allá. 


\section{Bibliografía}

Alonso Acero, Beatriz, Orán y Mazalquivir en la politica norteafricana de España, 1589-1639, Tesis doctoral, Madrid, Universidad Complutense, 1997.

Antonucci, Fausta (ed.), Lope de Vega, "Al caballero Juan Bautista Marino celebérrimo poeta napolitano", en Les idées du théâtre, 2013, en línea, $<$ http://idt.huma-num.fr/notice.php?id=478> [consulta del 17 de marzo de 2021].

—, "La polémique dans la dédicace à Marino de Virtud, pobreza y mujer de Lope de Vega (1) : à propos de quelques autres dédicaces de la Parte XX de comedias", Littératures classiques, núm. 83 (2014), pp. 83-96.

Arjona, J. H., "Did Lope de Vega write El lacayo fingido?", Studies in Philology, LI (1954), pp. 42-53.

—, "Ten plays attributed to Lope de Vega", Hispanic Review, XXVIII (1960), pp. 310-340.

ARTELOPE. Base de datos y argumentos del teatro de Lope de Vega, dir. J. Oleza, Valencia, Universitat de València, en línea, <http://artelope.uv.es> [consulta del 22 de marzo de 2021].

Artors, Florence d', "La polémique dans la dédicace à Marino de Virtud, pobreza y mujer de Lope de Vega (2): la superposition de la polémique cultiste et de la polémique théâtrale", Littératures classiques, núm. 83 (2014), pp. 97-113.

Berruezo Sánchez, Diana, Il Novellino de Masuccio Salernitano y su influencia en la literatura española de la Edad de Oro, Vigo, Academia del Hispanismo, 2015.

Blanco, Mercedes, "Las Soledades a la luz de la polémica", en La Edad del Genio. España e Italia en tiempos de Góngora, coord. B. Capllonch Bujosa, S. Pezzini, J. Ponce Cárdenas y G. Poggi, Pisa, Edizioni ETS, 2013, pp. 7-40. Cacho Casal, Rodrigo, "El événement barroco: Lope vs. Góngora", Mélanges de la Casa de Velázquez, XLII, 1 (2012), pp. 163-182.

Calderwood, Eric (ed.), Lope de Vega, La venganza venturosa, en Comedias de Lope de Vega. Parte X, coord. R. Valdés y M. Morrás, Lérida, MilenioUniversitat Autònoma de Barcelona, 2010, 3 vols., I, pp. 231-359.

Campbell, Ysla, "Nostalgia y transgresión en tres comedias de Lope de Vega", en Relaciones literarias entre España y América en los siglos XVI y XVII, coord. Y. Campbell, Ciudad Juárez, Universidad Autónoma de Ciudad Juárez, 1992, pp. 65-87.

—, "El comercio y las finanzas en el teatro de Lope de Vega", en Teatro, historia y sociedad. Seminario Internacional sobre Teatro del Siglo de Oro Español, ed. C. Hernández Valcárcel, Murcia-Ciudad Juárez, Universidad de MurciaUniversidad Autónoma de Ciudad Juárez, 1996, pp. 111-122.

Casariego Castiñeira, Paula (ed.), Lope de Vega, La pastoral de Jacinto, en Comedias de Lope de Vega. Parte XVIII, coord. A. Sánchez Jiménez y A. J. Sáez, Barcelona, Gredos, 2019, 2 vols., I, pp. 743-912. 
Case, Thomas E., Las dedicatorias de partes XIII-XX de Lope de Vega, Madrid, Castalia, 1975.

Conde Parrado, Pedro, Lope de Vega crítico de Góngora, París, e-Hispania Books, 2019, en línea, <https://books.openedition.org/esb/2173> [consulta del 15 de abril de 2021].

Di Pastena, Enrico, "La figura del mercader en El anzuelo de Fenisa, de Lope de Vega", Rilce, XXXIV, 1 (2018), pp. 127-150.

-, y Giulia Poggi (eds.), Lope de Vega, El castigo del discreto, en Comedias de Lope de Vega. Parte VII, coord. E. Di Pastena, Lérida, Milenio-Universitat Autònoma de Barcelona, 2008, 3 vols., I, pp. 201-326.

Dolfi, Laura, Il teatro di Góngora. "Comedia de Las firmezas de Isabela». I-Studio e nota filologica, Pisa, Cursi, 1983.

—, "Luis de Góngora: un Arte nuevo de hacer comedias diferente", Caliope, VIII, 1 (2002), pp. 37-54.

—, Luis de Góngora. Cómo escribir teatro, Sevilla, Renacimiento, 2011.

- (ed.), Luis de Góngora, Teatro completo, Madrid, Cátedra, 2016.

Fernández Rodríguez, Daniel, “¿Boccaccio, Giraldi y Firenzuola en una sola comedia? Lope de Vega y la reescritura de novelle", Boletín de la Real Academia Española, XCVIII, 317 (2018a), pp. 113-137.

—, "El número de personajes y las unidades de tiempo y lugar en el sistema de géneros teatrales de Lope: el caso de la comedia bizantina", Cuadernos AISPI. Estudios de lenguas y literaturas hispánicas, XI (2018b: Arte novísimo de estudiar comedias: las Humanidades Digitales y el teatro áureo, ed. A. Cassol y S. Boadas), pp. 95-114.

—, "No hay libro, por malo que sea, que no tenga alguna cosa buena': la difusión de las novelle de Sebastiano Erizzo y Niccolò Granucci en la España del Siglo de Oro", Anuario Lope de Vega. Texto, literatura, cultura, XXV (2019a), pp. 55-74.

-, Entre corsarios y cautivos: las comedias bizantinas de Lope de Vega, su tradición y su legado, Madrid-Fráncfort del Meno, Iberoamericana-Vervuert, 2019b.

- (ed.), Lope de Vega, Virtud, pobreza y mujer, en Comedias de Lope de Vega. Parte XX, coord. D. Fernández Rodríguez y G. Gómez Sánchez-Ferrer, Madrid, Gredos, 2 vols., 2021, II, pp. 355-569.

—, «Duques, princesas y arzobispos: la fecha de redacción de Virtud, pobreza y mujer, de Lope de Vega», Rassegna Iberistica, en prensa.

Ferrer Valls, Teresa, "Entre mercaderes anda el juego: El mercader amante de Gaspar Aguilar, Las firmezas de Isabela de Góngora y la anónima El mercader de Toledo", en El poder de la economía. La imagen de los mercaderes y el comercio en el mundo hispánico de la Edad Moderna, ed. C. Strosetzki, Madrid-Fráncfort del Meno, Iberoamericana-Vervuert, 2018, pp. 181-197.

Fichter, William L. (ed.), Lope de Vega, El castigo del discreto, Nueva York, Instituto de las Españas, 1925.

García-Reidy, Alejandro, "Difusión, presencia pública y fama en la polémica 
en torno a la oscuridad gongorina”, Boletín Hispánico Helvético, núm. 25 (2015), pp. 167-191.

Góngora, Luis de, Las firmezas de Isabela, en Teatro completo, ed. L. Dolfi, Madrid, Cátedra, 2016, pp. 67-261.

Iglesias Feijoo, Luis, "Secretos y supercherías en una comedia de Lope de Vega: El gran duque de Moscovia", Hipogrifo, V, 1 (2017), pp. 277-291.

Jammes, Robert, Etudes sur l'oeuvre poétique de don Luis de Góngora y Argote, Burdeos, Institut d'Études Ibériques et Ibéro-Américaines de l'Université de Bordeaux, 1967.

- (ed.), Luis de Góngora, Las firmezas de Isabela, Madrid, Castalia, 1984.

López Bueno, Begoña, "El cruce epistolar entre Lope y Góngora de 1615-1616. Revisión de fechas", en El Poeta Soledad. Góngora 1609-1615, ed. B. López Bueno, Zaragoza, Prensas Universitarias de Zaragoza, 2011, pp. 239-270.

McGrady, Donald, "Lope frente a Góngora: orígenes, relación y sentido de Virtud, pobreza y mujer y Las firmezas de Isabela", Hispanic Review, LXXI, 3 (2003), pp. 297-324.

- (ed.), Lope de Vega, Virtud, pobreza y mujer, Newark, Juan de la Cuesta, 2010. Morley, S. Griswold, y Courtney Bruerton, Cronología de las comedias de Lope de Vega, trad. M. a R. Cartes, Madrid, Gredos, 1968.

OlezzA, Joan, "Lope y los mercaderes. Un viaje de ida sin vuelta desde la Italia de los novellieri", en El poder de la economía. La imagen de los mercaderes y el comercio en el mundo hispánico de la Edad Moderna, ed. C. Strosetzki, Madrid-Fráncfort del Meno, Iberoamericana-Vervuert, 2018, pp. 287-303.

Osuna Cabezas, María José, Las Soledades caminan hacia la corte. Primera fase de la polémica gongorina, Vigo, Editorial Academia del Hispanismo, 2008.

Pedraza Jiménez, Felipe B. (ed.), Edición crítica de las Rimas de Lope de Vega, Madrid, Universidad de Castilla-La Mancha, 1993, 2 vols.

Pedraza Jiménez, Felipe B., y Pedro Conde Parrado (eds.), Lope de Vega, Arte nuevo de hacer comedias. Edición crítica. Fuentes y ecos latinos, Cuenca, Universidad de Castilla-La Mancha, 2016.

Peinado Guzmán, José Antonio, "Don Pedro González de Mendoza. Retazos históricos de un arzobispo franciscano en la Granada del siglo XVII", STVDIVM. Revista de Humanidades, núm. 21 (2015), pp. 77-103.

Prieto García-Seco, David, "Homónimos en el teatro áureo o la tiranía de la letra”, Rinconete (2020), en línea, <https://cvc.cervantes.es/el_rinconete/ anteriores/abril_20/21042020_01.htm> [consulta del 10 de marzo de 2021].

Restrepo Ramírez, Santiago, "Otra escaramuza más en la rivalidad temprana entre Lope y Góngora: el soneto esdrújulo de El caballero del milagro”, Studia Aurea, XI (2017), pp. 551-571.

RONCERo López, Victoriano, "El mercader y su mundo en El mercader amante y Las firmezas de Isabela", en El poder de la economía. La imagen de los mercaderes y el comercio en el mundo hispánico de la Edad Moderna, ed. C. Strosetzki, Madrid-Fráncfort del Meno, Iberoamericana-Vervuert, 2018, pp. 199-227. 
SÁnchez Jiménez, Antonio, Lope de Vega. El verso y la vida, Madrid, Cátedra, 2018.

SERÉs, Guillermo, "'El uso de España no admite las rústicas Bucólicas de Teócrito': la Trecena parte de comedias y el Arte nuevo", Rilce, XXVII, 1 (2011), pp. 216-243.

SмYтн, Philip, "El lacayo fingido: New Evidence against Lope's Authorship", Bulletin of the Comediantes, XXXIV, 1 (1982), pp. 45-50.

Tamariz, Cristóbal de, Novelas en verso, ed. D. McGrady, Charlottesville, University of Virginia, 1974.

TESO: Teatro Español del Siglo de Oro (base de datos textual en soporte CDRom), versión 3.00, Madrid, Chadwyck-Healey España, 1997-1998.

Tubau, Xavier, Una polémica literaria: Lope de Vega y Diego de Colmenares, Madrid-Fráncfort del Meno, Iberoamericana-Vervuert, 2007.

VegA, Garcilaso de la, Obra poética y textos en prosa, ed. B. Morros, Barcelona, Crítica, 2007.

Vega Carpio, Lope de, Arte nuevo de hacer comedias. Edición critica. Fuentes y ecos latinos, ed. F. B. Pedraza Jiménez y P. Conde Parrado, Cuenca, Universidad de Castilla-La Mancha, 2016.

—, El castigo del discreto, ed. E. Di Pastena y G. Poggi, en Comedias de Lope de Vega. Parte VII, coord. E. Di Pastena, Lérida, Milenio-Universitat Autònoma de Barcelona, 2008, 3 vols., I, pp. 201-326.

—, Lo cierto por lo dudoso, ed. S. Vuelta García, en Comedias de Lope de Vega. Parte XX, coord. D. Fernández Rodríguez y G. Gómez Sánchez-Ferrer, Barcelona, Gredos, 2021, 2 vols., I, pp. 283-448.

—, La cortesía de España, ed. E. Di Pinto, en Comedias de Lope de Vega. Parte XII, coord. J. E. Laplana Gil, Madrid, Gredos, 2013, 2 vols., I, pp. 491-648.

—, El dómine Lucas, ed. M. M. García-Bermejo Giner, en Comedias de Lope de Vega. Parte XVII, coord. D. Crivellari y E. Maggi, Barcelona, Gredos, 2018, 2 vols., I, pp. 977-1158.

-, El gran duque de Moscovia y Emperador perseguido, ed. M. Villar, en Comedias de Lope de Vega. Parte VII, coord. E. Di Pastena, Lérida, MilenioUniversitat Autònoma de Barcelona, 2008, 3 vols., I, pp. 457-587.

—, El marido más firme, ed. C. Monzó Ribes, en Comedias de Lope de Vega. Parte XX, coord. D. Fernández Rodríguez y G. Gómez Sánchez-Ferrer, Barcelona, Gredos, 2021, 2 vols., II, pp. 891-1060.

-, Peribánez y el comendador de Ocaña, ed. A. Blecua y G. Salvador, en Comedias de Lope de Vega. Parte IV, coord. L Giuliani y R. Valdés, Lérida, Milenio-Universitat Autònoma de Barcelona, 2002, 3 vols., I, pp. 413-544.

—, El príncipe despeñado, ed. A. Pozo y G. Serés, en Comedias de Lope de Vega. Parte VII, coord. E. Di Pastena, Lérida, Milenio-Universitat Autònoma de Barcelona, 2008, 3 vols., III, pp. 1241-1390.

—, "Prólogo dialogístico", en Comedias de Lope de Vega. Parte XVI, coord. F. d'Artois y L. Giuliani, Barcelona, Gredos, 2017, 2 vols., I, pp. 43-51. 
—, Quien ama no haga fieros, ed. P. Ruiz Pérez, en Comedias de Lope de Vega. Parte XVIII, coord. A. Sánchez Jiménez y A. J. Sáez, Barcelona, Gredos, 2019, 2 vols., II, pp. 467-614.

—, La serrana de Tormes, ed. E. Maggi, en Comedias de Lope de Vega. Parte XVI, coord. F. d'Artois y L. Giuliani, Barcelona, Gredos, 2017, 2 vols., II, pp. 133-288.

—, La venganza venturosa, ed. E. Calderwood, en Comedias de Lope de Vega. Parte X, coord. R. Valdés y M. Morrás, Lérida, Milenio-Universitat Autònoma de Barcelona, 2010, 3 vols., I, pp. 231-359.

-, Virtud, pobreza y mujer, ed. D. Fernández Rodríguez, en Comedias de Lope de Vega. Parte XX, coord. D. Fernández Rodríguez y G. Gómez SánchezFerrer, Barcelona, Gredos, 2021, 2 vols., II, pp. 355-569. 
